\title{
CONTENÇÃO TERRITORIAL E RETERRITORIALIZAÇÃO: O CASO DA LOCALIDADE DE CUMBUCO (CE)
}

\author{
EIDER DE OLIVINDO CAVALCANTE ${ }^{1}$ \\ JosÉ BorZACCHIELLO DA SILVA² \\ Universidade Federal do Ceará
}

\begin{abstract}
Resumo: Até o final da década de 1970, que marca a propagação dos conflitos entre especuladores imobiliários e grileiros, o litoral do Ceará era um sinônimo de liberdade para remanescentes indígenas e outros agrupamentos humanos que historicamente habitaram o litoral ou que migraram de outras partes do Estado fortemente funcionalizadas pelas atividades da pecuária e da agricultura. Todavia, no contexto da busca por novos territórios e setores para a acumulação capitalista, como também da captura de tempo livre e das demais relações sociais que escapavam à lógica da reprodução das relações de produção capitalista, o litoral passou a ser fortemente funcionalizado como território turístico motivando o contexto atual no qual as possibilidades de apropriação encontram-se cada vez mais sufocadas pelo conflito com a dominação do aparato estatal-empresarial. Nesse sentido, a partir do recorte espacial da localidade de Cumbuco - no município de Caucaia -, pretende-se contribuir com alguns subsídios para o entendimento da urbanização, das estratégias de contenção territorial e dos processos de reterritorialização no litoral do Ceará.
\end{abstract}

Palavras-chave: Cumbuco; Contenção Territorial; Reterritorialização.

\section{TERRITORIAL CONTAINMENT AND RETERRITORIALIZATION: THE CASE OF CUMBUCO (CE)}

Abstract: Until the end of 1970s, when the first conflicts between real estate speculators and land grabbers broke out, the coast of Ceará had remain a land of freedom for remaining indigenous people and other human groups that historically inhabited the coast or migrated from other parts of the state where agriculture and livestock activities largely prevail. However, in the context of the search for new territories and sectors to capitalist accumulation, as well as due to the capture of free time and

\footnotetext{
${ }^{1}$ Doutorando em Geografia pela Universidade Federal do Ceará. Contato: eidercavalcante@hotmail.com.

${ }^{2}$ Professor emérito da Universidade Federal do Ceará. Contato: borza@ufc.br.
} 
social relationships that escaped the logic of (re)production of capitalist relations, the coast has been strongly reorganized as tourist territory, generating a situation in which the possibilities of appropriation are increasingly thwarted by the conflict with the state-business apparatus. In this sense, focusing on the area of Cumbuco, in the municipality of Caucaia, we aim to contribute to an understanding of urbanization, territorial containment strategies, and reterritorialization processes in the coast of Ceará.

Keywords: Cumbuco; Territorial Containment; Reterritorialization.

\section{Introdução}

Cumbuco, localizado aproximadamente a $30 \mathrm{~km}$ (oeste) de Fortaleza, cercado de dunas, coqueiros e do mar, é uma das praias do litoral cearense mais procuradas pelos turistas e o lócus de uma pequena vila de pescadores (Vila do Cumbuco) em meio a grandes pousadas, hotéis, barracas de praia, boates, resorts, condomínios, mansões, lojas e toda infraestrutura que vem propiciar uma dinâmica que não existia no local há algumas décadas.

Essa pequena vila se consubstancia como residência de parte dos pescadores artesanais marítimos da localidade, que tiram da labuta pesqueira, em meio ao sol e ao mar, o sustento diário de suas famílias. Pescadores que, além de todas as dificuldades diárias do ato de pescar em uma pequena jangada, paquete ou bote, enfrentam ainda, por exemplo: a crise atual da pesca artesanal; o fato de grande parte das embarcações serem propriedade de armadores $^{3}$ e os conflitos com os atravessadores (marchantes). Além disso, hoje esses trabalhadores do mar têm sua rotina bombardeada por um leque de novos conflitos e contradições que colocam em cheque a reprodução dos mesmos enquanto cumbuqueiros ${ }^{4}$.

Sobre uma amenidade natural, um campo de dunas móveis, pouco antes da entrada de Cumbuco, pode-se ver, também, uma ocupação denominada Parazinho, fruto da saída de pescadores e filhos de pescadores de suas antigas residências, os quais estão construindo suas moradias sobre as dunas, distante do local de trabalho e convívio.

Cumbuco localiza-se no distrito sede do município de Caucaia, que se configura como o segundo maior município do Estado do Ceará no tocante à população, situando-se na Região Metropolitana de Fortaleza. Nesse sentido, Cumbuco tem uma posição privilegiada, pois, como bem observa Dantas (2010), o turismo cearense é predominantemente litorâneo e metropolitano.

Caucaia possui uma economia gerada principalmente pelo setor de serviços, que totaliza $67,7 \%$ do PIB do município, seguido pela indústria, com $29,86 \%$, e pela agropecuária, com 2,44\% (IPECE, 2008). O setor mais ativo também é responsável

\footnotetext{
${ }^{3}$ Segundo Diegues (1995), o armador de pesca é o proprietário de várias embarcações, mas não realiza a atividade de pescar.

${ }^{4}$ Como são conhecidos os "nativos" de Cumbuco.
} 
pela geração de 32,13\% dos empregos formais existentes em Caucaia. Segundo Teles (2005, p. 125), o setor terciário desempenha um papel fundamental na vida econômica da cidade. A autora afirma que, nos últimos dez anos “(...) este setor aumentou significativamente em decorrência da demanda crescente tanto por parte da população residente, como também da população flutuante que frequenta o município, sobretudo nos finais de semana, feriados e meses de férias". Ainda segundo Teles (2005, p. 130-131), “(...) o caráter da terceirização concentra-se, principalmente, nas atividades turísticas, em especial de alojamento e de transporte, além das agências de viagens".

Caucaia, que tem Cumbuco como principal destino turístico, figura em primeiro lugar no ranking do número de turistas que ingressam no Estado do Ceará via Fortaleza, seguido dos municípios de Aracati, Beberibe e Jijoca (SETUR, 2009b). Em outra pesquisa apresentada pela Setur (2009a), fazendo uma relação de dados entre 1999 e 2008, a praia de Cumbuco constitui-se como a preferida dos turistas, seguida pela de Canoa Quebrada, no município de Aracati ${ }^{5}$.

Cumbuco é uma das exceções turísticas do Ceará, já que neste Estado, ainda que as intenções iniciais dos gestores ${ }^{6}$ e dos empresários visassem os turistas estrangeiros, o turismo é predominantemente composto por turistas brasileiros, que representam 92,27 \% da demanda (SETUR, 2012). No entanto, em Cumbuco o universo turístico é constituído principalmente por estrangeiros, a maioria deles portugueses, suecos, finlandeses e noruegueses.

Associa-se à atividade do turismo uma nova efervescência imobiliária em Cumbuco nos últimos anos, principalmente no que diz respeito às segundas residências, as quais, por sinal, representaram a primeira fonte de exploração econômica da localidade mediante a construção do Loteamento Praia do Cumbuco no final da década de 1970. Observa-se a construção de uma gama de empreendimentos imobiliários de grande porte, voltados para brasileiros e principalmente estrangeiros que desejam investir ou simplesmente adquirir uma segunda residência para descanso ocasional nas terras cearenses.

Caucaia está entre as principais cidades do Estado do Ceará em número de residências secundárias, permanecendo em segundo lugar no ranking entre os anos de 1980 e 2000, atrás somente de Fortaleza. Em 2010, todavia, o município perdeu o segundo lugar para o município de Aquiraz ${ }^{7}$ (IBGE). Diferentemente de outras

\footnotetext{
${ }^{5}$ Os dados citados não incluem o litoral de Fortaleza.

${ }^{6}$ Benevides (1998, p. 51) destaca a intenção do Ceará de “(...) se constituir como um polo receptor da afluente demanda de setores de alta renda provenientes de vários países da economia pós-industrial". ${ }^{7}$ Merecedor de destaque é o fato de que dos cinco primeiros municípios no ranking do número de domicílios de uso ocupacional, somente Beberibe não faz parte da Região Metropolitana de Fortaleza, apesar de distar somente $75 \mathrm{~km}$ da capital cearense. Nesse sentido, Pereira (2006, p. 73) afirma que “(...) veraneio no Ceará é predominantemente litorâneo, de sorte que a ocupação ocorre em duas faixas retilíneas, que tem como nó central Fortaleza e se estende pelo restante do espaço litorâneo. O espaço de maior densidade, contudo, é o litorâneo metropolitano".
} 
localidades de Caucaia, como o Icaraí, por exemplo, que na década de 1970 teve uma forte valorização associada às segundas residências de moradores da classe média de Fortaleza, os proprietários de segundas residências no Cumbuco possuem elevados níveis de renda. Conforme levantamento da Cenários Pesquisa de Marketing, realizado no primeiro semestre de 2011, 42\% das famílias que têm ou pretendem adquirir uma residência de praia no Cumbuco detêm renda igual ou superior a R \$ 20 mil (O POVO, 22 de agosto de 2011).

Nos últimos dois anos, observa-se também a crescente presença de sul-coreanos no Cumbuco, em virtude da construção da Companhia Siderúrgica do Pecém (CPS), o que vem aquecendo o mercado imobiliário ligado às primeiras residências e trazendo consigo um leque de empreendimentos como comércios, restaurantes, imobiliárias e até templos religiosos que se dedicam a atender especificamente esse novo público na localidade praiana.

\section{Trilhas da formação territorial}

A formação territorial do Cumbuco se inicia aproximadamente na década de 1920, quando um pescador insatisfeito com a vida em Fortaleza decide viver em outro local $^{8}$. A pesca propiciou ao pescador conhecer grande parte do litoral cearense, mas ele acabou decidindo morar em uma praia que dista apenas $30 \mathrm{~km}$ de Fortaleza, utilizando como transporte a própria jangada e levando consigo sua família. A praia, denominada Cumbuco, era deserta e o acesso a ela se dava somente pelo mar e pela faixa de praia, sendo esta última forma somente possível quando a maré estava baixa. Posteriormente, com as notícias de pesca abundante na região, tanto no mar quanto nas inúmeras lagoas existentes à época, outras famílias começaram a se transferir para a região. Em 1977 a localidade possuía 120 famílias (PINHO, 1981; VIEIRA, 2000).

Até os finais da década de 1970, que marcaram a propagação dos conflitos com especuladores imobiliários e grileiros, o litoral representava um sinônimo de liberdade para remanescentes indígenas e outros agrupamentos humanos que historicamente o habitaram ou que decidiram migrar do interior do Estado, pois o litoral do Ceará, desde o período colonial, era visto como um local impróprio para a prática de atividades produtivas, como a agricultura, por exemplo, particularmente por conta das características físico-climáticas e da hostilidade indígena (LIMA, 2002; DANTAS, 2007). Nesse contexto, a ocupação portuguesa se dera somente de forma pontual no intuito da defesa do território e para o desenvolvimento da atividade portuária.

\footnotetext{
${ }^{8}$ Fato que coincide com o período em que se inicia a ocupação da Praia de Iracema em Fortaleza por famílias da "alta sociedade" cearense (DANTAS, 2002; NEVES, 2004).
} 
Tal realidade propiciou a consolidação de várias comunidades pesqueiras marítimas, as quais, ainda no período colonial, eram vistas com bons olhos pela Coroa, pois a marinha não tinha quadros suficientes para patrulhar a costa brasileira. Assim, em caso de algum conflito, os pescadores e suas colônias - as sentinelas avançadas do litoral - poderiam ser úteis na proteção do território, pois mesmo tido como impróprio ao desenvolvimento de atividades produtivas, o litoral se configurava em um território estratégico de defesa. Tal realidade se manteve, em grande medida, até os finais da década de 1970, mesmo com o crescimento de cidades como Fortaleza, Camocim, Aquiraz e Paracuru, predominando, então, as comunidades pesqueiras marítimas e seus modos de vida específicos.

A referida pouca funcionalização do litoral possibilitava certa mobilidade a estes trabalhadores do mar, que podiam se transferir para outros pontos do litoral à procura de bons pesqueiros, por conta da transgressão marinha, da movimentação dos campos de dunas, entre outras motivações. O fato possibilitou, já em tempos mais recentes, a formação e consolidação do Cumbuco, que até depois da construção da Vila (1978) recebeu famílias de pescadores de municípios como Beberibe. As próprias moradias, construídas com varas de madeira ou de palha caso do "Cumbuco Velho"-, que apresentam uma nítida influência das comunidades indígenas, como os históricos habitantes que viviam de forma nômade no litoral cearense, caracterizam essa mobilidade, pois facilmente eram construídas ou desfeitas, diferentemente de uma residência de alvenaria, por exemplo. $^{10}$

Entretanto, no contexto da busca por novos territórios e setores para a acumulação capitalista, como também pela subordinação do tempo livre e das demais relações sociais que escapavam à lógica da reprodução das relações sociais de produção capitalista, o litoral passou a ser fortemente funcionalizado ${ }^{11}$, gerando uma série de conflitos. Dantas (2006) destaca que os anos 1970 simbolizam um movimento importante de transformação e incorporação do litoral cearense à sociedade de consumo ${ }^{12}$. E com esse movimento, "o pescador, que antes se batia contra o mar e seus elementos para garantir sua sobrevivência, tem que lutar em terra parra garantir sua permanência nas praias". (DANTAS, 2007, p.272).

Tratando especificamente do Cumbuco, em 1972 um empreendedor conheceu a comunidade e pouco depois iniciou estudos de viabilidade e de reconhecimento da área. Naquele período tornou-se comum a vinda de visitantes convidados pelo empreendedor com o intuito de conhecer o local e de realizar futuros negócios.

\footnotetext{
${ }^{9}$ Como atualmente os moradores chamam o Cumbuco antes de se tornar Vila.

${ }^{10}$ Essa realidade manteve-se mesmo com as históricas políticas de normatização e fixação no território, principalmente com a criação das "Colônias de Pescadores", em 1922, que apresentam uma estrutura semelhante às "guildas" espanholas, em que podem exercer a profissão somente os pescadores cadastrados em suas respectivas colônias (DIEGUES, 1995; DANTAS, 2003).

${ }^{11} \mathrm{O}$ tema da valorização e da funcionalização do litoral do Ceará foi desenvolvido em Autor (2012).

${ }^{12}$ Movimento que irá se intensificar na segunda metade dos anos 1980.
} 
Parte das terras que futuramente se tornariam a Vila do Cumbuco e o Loteamento Praia do Cumbuco pertencia à Marinha do Brasil, sob o Decreto-Lei ${ }^{\circ}$ 9.760, de 15 de setembro de 1946, que afirma que as terras de marinha vão até 33 $\mathrm{m}$ da linha da preamar e seus acrescidos, podendo chegar, na prática, até $100 \mathrm{ou}$ $200 \mathrm{~m}$ de orla. E a empresa recém-criada pelo empreendedor, “(...) sabedora deste fato, solicitou então que a União fizesse a demarcação das terras naquela praia” (PINHO, 1981, p. 23). O restante das terras, segundo dados da empresa, “(...) era uma fazenda abandonada, mas tinha uma escritura desde 1848. Essa Fazenda era dividida em duas partes (Parnamirim e Jabaquara), e pertencia a uma senhora cujo nome era Caetana Tereza das Maravilhas, com Registro Imobiliário em 1892" (CONSTRUTORA CUMBUCO LTDA, 1997, p. 1).

O empreendedor articulou-se com a Prefeitura de Caucaia, com o Governo do Estado do Ceará, com o Ministério do Trabalho e a Capitania dos Portos, entre outros órgãos e entes políticos, formando uma verdadeira frente de transformação do litoral de Caucaia. Nesse sentido, após uma série de discussões e da elaboração de alguns planos que procuravam decidir o futuro daqueles históricos povoadores do litoral, deliberou-se construir a Vila do Cumbuco ${ }^{13}$. Dessa forma, a Construtora Cumbuco LTDA ficou responsável pelo fornecimento do material de construção de 80 casas em troca de alguns benefícios da Prefeitura de Caucaia, do Governo do Estado, da Superintendência Nacional do Abastecimento (SUNAB) e do Ministério do Trabalho. Segundo Pinho (1981, p. 25-26, grifos da autora) os benefícios foram:

a) A prefeitura de Caucaia concedeu à construtora isenção de impostos referentes a toda a área a ser loteada, o que significa que, enquanto lhe pertencer, nenhum imposto incidirá sobre a terra. No entanto, a partir da venda de cada lote, a prefeitura começa a cobrar impostos, agora do novo proprietário.

b) Ao Governo do Estado coube a instalação de energia elétrica na nova vila, passando, obrigatoriamente, pelo loteamento. Também este se comprometeu a entregar asfalto líquido à construtora para ser aplicado na estrada que vai da praia da Tabuba até a Vila.

c) À SUNAB coube o fornecimento de Cr\$200.000,00 para compra de alimentos destinados aos operários que estivessem trabalhando na obra da nova vila.

d) O Ministério do Trabalho contribuiu permitindo que as casas fossem construídas em regime de mutirão. Isto significa que os

\footnotetext{
${ }^{13}$ A construção da Vila do Cumbuco representou o maior marketing para o turismo e o veraneio no Cumbuco, convidando "os civilizados [turistas europeus] a descobrirem este paraíso" que, além do sol eterno, das águas tépidas e dos bons ventos, oferecia contato com uma vila de pescadores, presenciando suas práticas, seus costumes e um leque de experiências com uma comunidade tradicional e seu modo de vida específico (O POVO, 12 ago. 1988).
} 
operários trabalhariam sem carteira assinada, ficando o empregador, no caso a Construtora Cumbuco, desobrigado de cumprir qualquer encargo trabalhista, tal como pagamento de décimo terceiro mês, previdência social, férias e outros direitos que são devidos aos trabalhadores com carteira assinada, ou seja, que mantenham vínculo empregatício com a firma empregadora.

No dia 7 de janeiro de 1978, às 16 horas, foi inaugurada A Colônia Z-7 de pescadores de Cumbuco. Foram construídas 80 casas para as famílias que permaneceram, mas, conforme dados oferecidos pela Colônia e pelos documentos da construtora, foram entregues apenas 79 casas, pois uma família optou pelo recebimento de uma indenização e foi morar no litoral do Rio Grande do Norte ${ }^{14}$.

No intuito de enfatizar que o processo se deu sem grandes conflitos, os documentos oficiais da construtora mencionam que apenas esta última família destacada decidiu receber a indenização e foi morar no litoral do Rio Grande do Norte, deixando de nomear as outras cerca de 40 famílias que, ainda aproveitando os últimos momentos da referida mobilidade do litoral cearense, se mudaram para outras paragens do litoral cearense e nordestino, como uma família que fora para uma comunidade pobre no litoral de Fortaleza, conhecida como Arpoador, por exemplo.

As casas "doadas" eram divididas em oito "vilas"" (quarteirões) formadas por 10 casas geminadas constituídas por dois quartos, sala, cozinha (com uma pia), banheiro (com um tanque d'água e aparelho sanitário, sem descarga e sem tampa), tanque para lavar roupas, fossa e sumidouro. Não existia instalação hidráulica ou elétrica, apenas dois poços para toda a vila, nem havia calçada nas casas (CONSTRUTORA CUMBUCO LTDA, 1997; PINHO, 1981). Estas foram construídas em lotes de $180 \mathrm{~m}^{2}$, possuindo $36 \mathrm{~m}^{2}$ de área construída (seis por seis), $42 \mathrm{~m}^{2}$ de cobertura, paredes de alvenaria, sem revestimento (reboco) e somente com pintura externa na cor branca; portas de madeira comum e sem forramentos; piso interno vassourado na sala e nos dois dormitórios; piso cimentado na cozinha e no banheiro (PINHO, 1981).

Os cumbuqueiros, que moravam de modo espraiado em toda a área que compreende o Cumbuco, foram realocados nesta pequena vila de $50.616 \mathrm{~m}^{2}$ distribuída em $23.400 \mathrm{~m}^{2}$ de área loteada, $22.896 \mathrm{~m}^{2}$ de ruas e $4.320 \mathrm{~m}^{2}$ para serviços comunitários, esportes e sede da colônia. Da área loteada, apenas 14.400 $\mathrm{m}^{2}$ foram realmente ocupados naquele momento, ficando 48 lotes destinados ao crescimento da Vila ${ }^{16}$.

\footnotetext{
${ }^{14} \mathrm{~A}$ casa que ficara vazia, então, foi destinada a sediar a maternidade.

${ }^{15} \mathrm{Na}$ linguagem dos moradores da localidade.

${ }^{16}$ Os cinco quarteirões que ficaram vazios foram sendo ocupados aos poucos pelos filhos dos moradores que casavam e começavam a formar suas famílias. Todavia, na metade da década de 1980,
} 
O restante das terras do Cumbuco foi destinado à construção do Loteamento Praia do Cumbuco, que teve seu primeiro lote vendido oito meses após a construção da Vila. Toda a área loteada foi beneficiada com energia elétrica, via de acesso asfaltada e linha de ônibus que fazia o percurso Cumbuco/Caucaia cinco vezes ao dia. Assim, em meados dos anos de 1980, “(...) próximo à Vila onde antigamente só existiam dunas e coqueirais, começam a surgir quarteirões de casas de veraneio" (PINHO, 1981, p. 6).

Em 1986, período marcado pela força da urbanização litorânea, o jornal O Povo publicou que “(...) no Cumbuco, o vilarejo persiste, mas também está sufocado pelas mansões", em reportagem que tratava das pressões sofridas pelos pescadores para cederem lugar aos especuladores imobiliários em Fortaleza e na Região Metropolitana (O POVO, 7 de fevereiro de 1986). Ainda em 1986, em outra reportagem do Jornal O Povo, lia-se a afirmativa de que o “(...) Cumbuco tem 100 casas de pescadores e 200 de veraneio que, sem dúvida, são as mais belas da Costa Litorânea Cearense" (O POVO, 12 de outubro de 1986).

No final da década de oitenta, já com a construção do hotel Saint Tropez des Tropiques, o Cumbuco se torna um marco para o turismo cearense, especificamente em relação ao turismo internacional, pois chegavam os primeiros voos charters, que traziam turistas diretamente para o empreendimento hoteleiro francês pela empresa aérea Air France ${ }^{17}$. A empresa espalhava naquele momento por toda a Europa cartazes e folders da “(...) operadora de turismo 'El Condor', convidando os civilizados a descobrirem este paraíso, um Éden de sol eterno, águas tépidas e brisa amena que suaviza o calor.” (O POVO, 12 de agosto de 1988).

\section{Cumbuco, Parazinho e a reterritorialização}

No intuito de melhor entender a realidade que se constrói, propõe-se considerála com base na dinâmica dos múltiplos territórios porque, mesmo que a hegemonia do poder estatal-empresarial seja pretensamente uniterritorial, existem outros circuitos de poder que desenham complexos territórios e territorialidades. No âmago desse pensamento, pretende-se entender o território mediante a relação entre dominação e apropriação, ${ }^{18}$ procurando encontrar os múltiplos sujeitos e poderes que formam o território (Estado, empresas, instituições, grupos sociais/culturais, indivíduos), de modo que ele seja visto não somente como um

\footnotetext{
os lotes vazios que restavam foram ocupados pelos pescadores de Beberibe, que se transferiram para o Cumbuco por conta do auge da pesca do camarão na localidade e de conflitos por terra em seu município de origem.

${ }^{17}$ Entre o período de fevereiro de 1989 e janeiro de 1990, cerca de 1100 franceses chegaram pelo aeroporto de Fortaleza para se hospedar no citado hotel (O POVO, 19 de janeiro de 1990).

${ }^{18}$ Ver em Haesbaert $(2002,2005,2007,2008,2009)$.
} 
constructo material econômico, mas em suas múltiplas dimensões. O território, para Haesbaert (2002, p. 121), é tido como

(...) produto de uma relação desigual de forças, envolvendo o domínio ou o controle político-econômico do espaço e sua apropriação simbólica, ora conjugados e mutuamente reforçados ora desconectados e contraditoriamente articulados. Esta relação varia muito, por exemplo, conforme as classes sociais, os grupos territoriais e as escalas geográficas que estivermos analisando. Como no mundo contemporâneo vive-se concomitantemente uma multiplicidade de escalas, numa simultaneidade atroz de eventos, vivenciam-se também, ao mesmo tempo, múltiplos territórios.

Nesse sentido, pode-se conceituar a argumentação que afirma que o Cumbuco, como praticamente todo o litoral cearense, não era considerado propício para a prática de atividades produtivas como a agricultura, por exemplo, configurando-se em um território de reserva - na perspectiva de Harvey (2005) e Robira (2005) ${ }^{19}$. Por meio dessa linha de raciocínio construída com base na pouca funcionalização (dominação) do litoral, que abriu caminho para a apropriação de remanescentes indígenas e outros agrupamentos humanos, compreende-se a realidade que propiciou a consolidação de várias comunidades pesqueiras marítimas ${ }^{20}$ e seus modos de vida específicos no litoral do Ceará.

Como afirma Diegues, com um isolamento relativo, essas populações construíram modos de vida particulares, envolvendo uma "grande dependência dos ciclos naturais, conhecimento profundo dos ciclos biológicos e dos recursos naturais, tecnologias patrimoniais, simbologias, mitos e até uma linguagem específica, como sotaques e inúmeras palavras de origem indígena e negra (DIEGUES, 1996, p 14-15)”. As comunidades pesqueiras marítimas se caracterizam, segundo Lima (2006, p. 40),

(...) por um processo de trabalho artesanal que se dá no mar (a exemplo da pesca de peixe, de arraia e lagosta), marcado pela hierarquia baseada no "segredo", e em terra, com a realização de trabalhos artesanais (bordados, labirintos, rendas, fabricação e reparos dos artefatos de pesca) e manuais (pequenos plantios de

\footnotetext{
${ }^{19}$ Harvey (2005, p. 117) usa a expressão "territórios não-capitalistas" e Robira (2005, p. 10), também trabalhando com o pensamento de Harvey, usa a conceituação de "territórios-reservas" para tratar do que a autora denomina de colonização de áreas metropolitanas.

${ }^{20}$ Para Lefebvre, citado por Haesbaert $(2008$, p. 21), “(...) tanto mais o espaço é funcionalizado, tanto mais ele é dominado pelos 'agentes' que o manipulam tomando-o unifuncional, menos ele se presta à apropriação. Por quê? Porque ele se coloca fora do tempo vivido, aquele dos usuários, tempo diverso e complexo".
} 
subsistência e o extrativismo vegetal). Nos dois espaços registram-se relações fundamentadas por laços de afetividade, de parentesco e apadrinhamento, a religiosidade e o lúdico. Em essência, há vínculos e referenciais construídos a partir da relação sociedade-natureza, da produção de meios de vida, de relações sociais (as mais variadas, indo do "escambo" ao comércio internacional), do uso do espaço social, da temporalidade cíclica (mas, também, sob a influência da temporalidade linear) e da experiência pesqueira na zona costeira.

O Cumbuco, de forma particular no curso da história, constituiu-se numa comunidade pesqueira marítima, com seu modo de vida específico, praticando a pequena produção mercantil ${ }^{21}$. Instituiu-se como território de uso, ${ }^{22}$ apropriado pelos sentidos, garantindo a reprodução da vida dos cumbuqueiros. Não somente um território numa dimensão concreta e econômica que se caracteriza pela atividade da pequena produção mercantil, mas também numa dimensão simbólica e efetiva, permeada de representações e de todo um imaginário mitológico e religioso, como afirma Bonnemaison (2002, p. 120) referindo-se às aldeias de Madagascar: “(...) a terra não era apenas um lugar de produção, mas também um suporte de uma visão de mundo".

O território da reprodução da vida dos cumbuqueiros se configurava de modo bem mais vasto e fluido do que o território camponês, por exemplo, abrangendo também a porção marinha - de uso comum -, em que, até os dias atuais, os bons pesqueiros são guardados como segredo de família e localizados com base num complexo sistema de triangulação de pontos. ${ }^{23}$ Segundo os relatos de um cumbuqueiro, “(...) o pescador sai do mar uma hora da manhã e põe suas redes (...) marca somente pelas serras. Sem nunca ter ido à escola (...) muitas vezes nunca viu nem um GPS e ele faz a marcação da pescaria naquele ponto $\mathrm{x}$, como se fosse as coordenadas, só pelas serras e não vai ter erro".

Entretanto, a partir do final da década de 1970, o Cumbuco passou a ser fortemente funcionalizado como território turístico, na perspectiva de Cruz

\footnotetext{
${ }^{21}$ A principal atividade econômica do Cumbuco era pesca artesanal voltada, sobretudo, para a venda, mesmo que parte da produção fosse destinada à subsistência familiar. Semanalmente, no período de maré baixa, os marchantes, oriundos de Fortaleza ou Caucaia, chegavam com seus jipes para a compra dos pescados. E com o intuito de complementar a subsistência das famílias, plantava-se, nas vazantes, arroz, feijão, milho, batata doce, mandioca, jerimum, entre outros produtos, além de se manter criações de animais de pequeno porte, como porcos e galinhas.

${ }^{22}$ Haesbaert (2007), trabalhando com o pensamento de Jean Gottman, usa a expressão território como abrigo para distinguir do espaço funcionalizado pelo aparato estatal-empresarial denominado território como recurso.

${ }^{23}$ Como observa Diegues (1996).
} 
$(2002)^{24}$, motivando o contexto atual em que possibilidades de apropriação encontram-se cada vez mais sufocadas pelo conflito entre a dominação do aparato estatal-empresarial e transformados, pelo valor contábil, em mercadoria (HAESBAERT, 2007).

Assim, com a ocupação dos últimos lotes vazios da Vila, a forte ação dos especuladores imobiliários que insistentemente tentam comprar os imóveis ou parte deles e o crescimento das famílias, os cumbuqueiros, ainda nos anos de 1990, começam a se deparar com o problema da falta de moradia. A situação é lembrada em praticamente todas as conversas formais e informais realizadas durante a pesquisa, principalmente no que se refere aos filhos e filhas que formaram suas famílias e não conseguem adquirir uma moradia no local de origem.

Em pesquisa direta, verificou-se que 67,3\% das famílias do Cumbuco possuem filhos que formaram família morando na casa dos pais ou que fizeram um "puxadinho" 25 na casa deles. Foram encontradas apenas duas ocorrências de filhos que constituíram família e conseguiram comprar outra casa no Cumbuco, e outras três de famílias que conseguiram alugar um "quartinho" na Vila.

Outra realidade observada nesta investigação é a fragmentação dos lotes originais de $180 \mathrm{~m}^{2}$, que foram divididos em média em duas partes, chegando a até mais de quatro partes, sendo que $22,5 \%$ dos lotes originais tiveram partes vendidas para especuladores, $35,4 \%$ tiveram partes cedidas para os filhos construírem seus "puxadinhos" e 4,7\% tiveram uma parte vendida e outra cedida. Cerca de 62,9\% dos cumbuqueiros já receberam oferta de compra de suas casas numa variação de 75 a 350 mil reais, pois os preços se alteram dependendo do tamanho do lote e da proximidade da praia.

Segundo as palavras de um cumbuqueiro entrevistado, os moradores do Cumbuco, acostumados com os poucos ganhos obtidos na prática da pesca ou nas atividades de pedreiro, caseiro, zelador, entre outras, ficam facilmente vislumbrados pelos altos preços oferecidos por suas casas. O interlocutor afirma ainda que alguns que moravam mais próximos à praia até conseguiram vender suas moradias e comprar outra nas proximidades da escola municipal, onde se localizam os quarteirões mais afastados do mar. Porém, a grande maioria rapidamente gasta $\mathrm{o}$ dinheiro e vai morar em outras localidades nas quais o preço das moradias é menos elevado.

Ainda segundo as palavras do nosso interlocutor, “(...) foi chegando muito turista, tanto brasileiro como estrangeiro, e foram botando dinheiro nas casas aqui e

\footnotetext{
${ }^{24}$ Coadunando com a ideia da autora de que nenhum território é turístico em si, mas um constructo de relações sociais, acredita-se que o território turístico seja produto da ação do poder estatal-empresarial que tenta controlar os fluxos turísticos para pontos previamente definidos que são praticamente inventados ou que já possuíam certa valorização espontânea, além do tensionamento ao eterno nomadismo (CRUZ, 2002; KNAFOU, 2001).

${ }^{25}$ Uma pequena construção anexa à residência principal, construída normalmente na parte não edificada do lote original.
} 
o pessoal foi vendendo e vendendo (...) vendendo essas casas porque é muito dinheiro uma casa no Cumbuco". Vale assinalar que a grande maioria dos cumbuqueiros que venderam somente partes dos lotes não fizeram as transações por milhares de reais; a grande maioria dessas partes foi vendida ainda da década de 1980, por vezes em geração anterior e a preços irrisórios.

Diante dessa problemática de moradia, nos anos 2000 algumas famílias chegaram até a limpar e marcar um terreno que se situa na localidade da Lagoa do Barro, mas, diante de uma série de dificuldades e contratempos, essa proposta foi abortada, como bem lembra outro cumbuqueiro que posteriormente, à custa de muito esforço, conseguiu construir sua casa em outra parte da localidade da Lagoa do Barro.

Retoma-se a exposição iniciada no inicio do presente artigo, pela qual se põe em destaque a existência do Parazinho - uma ocupação sobre o campo de dunas, oriunda da saída de pescadores e filhos de pescadores de suas antigas residências. Constatou-se que $58,6 \%$ das famílias ${ }^{26}$ do Cumbuco apresentavam filhos que formaram família ${ }^{27}$ morando na localidade do Parazinho/ Tabuba e verificou-se, também, a ocorrência de outros filhos que foram para as localidades de Lagoa do Barro, Icaraí, Garrote e Pecém, esta ultima no município de São Gonçalo do Amarante.

Uma cumbuqueira que hoje reside no Parazinho afirma: "Meu sonho era ter meu lugarzinho, ter minha casa para morar, mas por ele (seu marido) estava lá morando na casa do pai dele e da mãe dele até hoje. Vivendo naquele ninho, num só ninho (...). Eu dizia assim: eu quero nem que seja uma casa de palha, mas que seja minha".

O Parazinho, que a cada visita surpreende com sua constante expansão, teve suas primeiras casas construídas na década de 1990, mas sua ocupação consolidouse somente nos anos 2000. Uma associação, ainda nos anos de 1990, realizou uma série de reuniões com moradores do Cumbuco que estavam precisando de residências e articulou a "doação" de terrenos para que eles pudessem construir suas casas, contexto no qual os moradores, para receberem o terreno, tinham de pagar regularmente a mensalidade da associação. Em pouco tempo as casas, que naquela época eram de taipa, começaram a ser construídas e, ainda, alguns terrenos foram adquiridos para fins de uma futura negociação.

Até o presidente da Colônia de Pescadores deixou de morar no Cumbuco e construiu sua casa na localidade da Tabuba, afirmando que saiu de seu local de nascimento pelo fato de não aguentar mais tanto barulho de carros, som alto e tanta gente. E o pai do interlocutor está vendendo a última parte no lote que lhe restou

\footnotetext{
${ }^{26}$ Importante destacar que algumas famílias apresentavam, ao mesmo tempo, filhos que formaram família morando na casa dos pais, como também morando na localidade do Parazinho.

${ }^{27}$ Sem contabilizar irmãos, tios, sobrinhos, entre outras formas de parentesco que também foram constatadas.
} 
para ir morar na Tabuba porque trabalha consertando as embarcações, no meio do calçamento, ameaçado a todo o momento pelos carros que passam.

Nos dias correntes a ocupação está fortemente adensada, com a grande maioria das casas construídas em alvenaria, num misto de moradias precárias e outras bem estruturadas. Não obstante, a infraestrutura disponível é precária, já que as ruas não possuem calçamento, não existe ainda saneamento básico e nem coleta de lixo, havendo apenas energia elétrica. O processo de urbanização e de modernização do litoral, como diz Lefebvre (2001), provoca também um processo de urbanização desurbanizante e desurbanizada.

Uma cumbuqueira residente no Parazinho, ao ser questionada sobre a quantidade de cumbuqueiros que saem para morar na localidade, é enfática: “(...) Tem muita, muita e ainda é saindo mais. Até porque lá futuramente só vai ter lugar para os gringos, para os estrangeiros, né".

Mas como entender esse processo de saída dos cumbuqueiros do Cumbuco? À primeira vista encontrar-se-ia a explicação para tal contexto no entendimento de que os turistas - beneficiados pela fluidez e dinamicidade da globalização - tornamse extraterritoriais, vivendo em eterna mobilidade como verdadeiros globetrotters (BAUMAN, 1999), e os cumbuqueiros, por sua vez, sofrem um processo de desterritorialização, perdendo suas raízes e seu território. Na contramão desse raciocínio, Carlos (1996, p. 14) afirma que

O debate em torno do processo de globalização remete-nos a uma discussão sobre o mercado mundial e traz, na sua esteira, como fundamento da análise, as considerações sobre as novas relações espaço/tempo. Alguns autores veem nesse novo processo a desterritorialização do homem e de suas atividades. Aqui nosso caminho é radicalmente oposto. Cada vez mais o espaço se constitui numa articulação entre o local e o mundial, visto que, hoje, o processo de reprodução das relações sociais dá-se fora das fronteiras do lugar específico até há pouco vigentes. Novas atividades criam-se no seio de profundas transformações do processo produtivo, novos comportamentos se constroem sob novos valores a partir da constituição do cotidiano.

Haesbaert (2007, p. 37) afirma que, ao contrário da suposta extraterritorialidade dos globetrotters ou turistas globalizados, esta nova elite planetária vive numa multiterritorialidade, tendendo, "(...) de certa forma, a vivenciar, concomitante, de uma enorme gama de diferentes territórios elou territorialidades". Ainda segundo o autor, o processo que ele denomina de des-territorialização (com hífen), estaria sempre dialetizado como um processo de desterritorialização e reterritorialização, pois ninguém vive sem território. Para o autor, a existência humana é uma existência territorial (HAESBAERT, 2004, p. 36). Dessa maneira, ao mesmo 
tempo em que os cumbuqueiros estão perdendo seu território, estão se reterritorializando no Parazinho, mas tal processo não ocorre de forma espontânea ou sem perdas.

Bauman (1999) e Haesbaert (2007), mesmo chegando a conclusões opostas, destacam que os processos que garantem ao turista viver em constante mobilidade tornam os agrupamentos humanos mais desprovidos quanto mais localizados e imobilizados $^{28}$. Em outras palavras, “(...) alguns desfrutam da nova liberdade de movimentos sans papiers. Outros não têm permissão para ficar nos seus lugares pela mesma razão" (BAUMAN, 1999, p. 96). Segundo Lefebvre,

Só emergem as personalidades olímpicas, grande burguesia que corresponde em nosso tempo à antiga aristocracia da qual recolhe as migalhas. As personalidades olímpicas não têm vida cotidiana, se bem que as imagens que as popularizam lhes atribuam, precisamente, uma cotidianidade superior. Em última análise, o Olímpico não tem nem domicílio fixo; ele reconstitui na opulência, com os meios do poderio, a vagabundagem "livre", o nomadismo; vive em seu iate, vai de palácio a palácio ou de um castelo a outro. Está acima do "habitante". Para o comum dos mortais, o Olímpico, criatura de sonho, fornece imagens sensíveis (vendidas muito caro) do imaginário. O possível, todo o possível, se encarna. É uma outra cotidianidade, mal reconhecida e, no entanto, reconhecida: piscina, telefone branco, mesa de estilo. Mas há uma transcendência: o Olímpico não habita mais. ${ }^{29}$ Quanto ao habitante, fixado no solo, a cotidianidade o sitia, o imerge, o engole (LEFEBVRE, 1991, $\mathrm{p}$. 103, grifo nosso).

Alves (2011) é enfática ao afirmar que a imobilidade física é associada a uma imobilidade social, associada às formas de habitações precárias, em ocupações irregulares, sem acesso a benfeitorias sociais, como infraestrutura básica ou instituições de ensino e saúde.

No entanto, a localização (fixação) é acompanhada pelo movimento, mas um movimento imposto. Os cumbuqueiros, para a garantia de mobilidade das personalidades olímpicas (turistas), "estão se movendo porque foram empurrados" (BAUMAN, 1999, p. 101). Foram primeiramente empurrados para a Vila, depois imobilizados pelo fato de o pequeno espaço destinado aos pescadores ter sido

\footnotetext{
${ }^{28}$ Haesbaert (2009) vai tratar da i-mobilidade (com hífen), representando a dialética entre a mobilidade e a imobilidade.

${ }^{29}$ A referência ao fim do habitar não se refere a uma suposta extraterritorialidade, pois para o referido autor as relações sociais são também espaciais por excelência, como também aponta Carlos (2011), mas diz respeito à revelação de um espaço sem espessura, calcado no fim do flanar no sentido baudelairiano e na construção de um tempo efêmero e de um espaço amnésico (CARLOS, 2001).
} 
cercado e praticamente engolido pelo Loteamento Praia do Cumbuco, não havendo meios para sua expansão nem para a garantia de suas práticas diárias. E, nesse contexto, novamente empurrados, desta vez em direção ao Parazinho.

Para Bonnemaison (2002, p. 108, grifo nosso), “(...) nesses lugares de aculturação e de desenraizamento, o único meio de sobrevivência que resta a um grupo é constituir um novo território, por ínfimo que seja e, se isso não for possível, recriar um num outro lugar, no sonho e no mito..."

Segundo Bauman (1999, p. 191), que chega a apresentar a estratificação social com base no grau de mobilidade, o mundo foi feito sob medida para o turista, destacando que "(...) o que se chama hoje de 'globalização' gira em função dos sonhos e desejos dos turistas".

Haesbaert (2009, p. 95), ao tratar das dinâmicas de i-mobilização sob um plano geral que ele chama de sociedade de des-controle e de in-segurança, ${ }^{30}$ afirma que esse processo “(...) se desdobra entre o fechamento e a abertura, fluidez e fixação territorial (...) constitui o que denominamos em sentido amplo, de estratégias territoriais e, obviamente, também sociais de contenção". ${ }^{31}$

Os turistas que detêm o controle da mobilidade e dos fluxos podem vivenciar a multiterritorialidade entre seus países de origem, o Cumbuco e onde mais tiverem interesse, já os cumbuqueiros, que ficam à margem deste controle e, pelo contrário, sofrem tentativas de contenção territorial, são ora imobilizados ora empurrados, vivenciando uma forte precarização social (HAESBAERT, 2009).

\section{Considerações Finais}

Os trabalhadores do mar, que historicamente desfrutaram de certa mobilidade devido a pouca funcionalização do litoral cearense, sofreram seu primeiro processo de contenção do território de reprodução da vida durante a própria construção da Vila do Cumbuco, em que foram organizados (contidos) e fixados (imobilizados). Realidade esta que é expressa numa reportagem de jornal publicada um ano depois da construção da Vila: "Considera-se, hoje, o Cumbuco um exemplo de como organizar uma sociedade pobre, sem criar problemas sociais" (O POVO, 30 de novembro de 1979, grifo nosso). No entanto, a fixação (imobilidade) é acompanhada, nos dias correntes pelo movimento, mas um movimento imposto. Os cumbuqueiros estão sendo mobilizados (empurrados) do Cumbuco. O

\footnotetext{
${ }^{30}$ Salvo as diferenças, Lefebvre (1999) usa a denominação de sociedade super-repressiva, que pode chegar ao extremo de sociedade terrorista.

${ }^{31} \mathrm{Em}$ trabalhos anteriores, o autor trabalhou com o conceito de exclusão territorial (HAESBAERT, 1995) e, posteriormente, passou a trabalhar com a conceituação de reclusão (HAESBAERT, 2004). Hoje tem apresentado o que ele chama de "quase conceito" de contenção territorial (HAESBAERT, 2009), o que mostra que sua teoria está sempre aberta à realidade.
} 
Parazinho, assim como a localidade da Lagoa do Barro, apresenta-se, nesse sentido, como uma estratégia de resistência dos cumbuqueiros em manter ainda uma relação íntima com o Cumbuco, que supera a questão da moradia. O Cumbuco é o sentido do Parazinho.

\section{Bibliografia}

ALVES, Glória da A. (2011) A mobilidade/imobilidade na produção do espaço urbano. In: CARLOS, Ana Fani A.; SOUZA, Marcelo L. de; SPÓSITO, Maria E. B. (orgs.). A produção do espaço urbano. São Paulo: Contexto. pp. 109-122.

BAUMAN, Zygmunt. (1999) Globalização: As consequências humanas. Rio de Janeiro: Jorge Zahar Editor.

BENEVIDES, Ireleno P. (1998) Turismo e o Prodetur: Dimensões e olhares em parceria. Fortaleza: Edições UFC.

BONNEMAISON, Joel. (2002) Viagem em Torno do Território. In: CORRÊA, Roberto L.; ROSENDAHL, Zeny (orgs.). Geografia Cultural: um século (3). Rio de Janeiro: UERJ. pp. 83-131.

CARLOS, Ana Fani A. (1996) O lugar no/do mundo. São Paulo: Hucitec.

. (2001) Espaço-tempo na metrópole: a fragmentação da vida cotidiana. São Paulo: Editora Contexto.

. (2011) A Condição Espacial. São Paulo: Editora Contexto, 2011.

CASCUDO, Luís da C. (1957) Jangadeiros. Série Documentário da Vida Real, no 11. Rio de Janeiro: Ministério da Agricultura.

. (2002) Jangada: uma pesquisa etnográfica. São Paulo: Global.

CAVALCANTE, Eider de O. (2012) Modernização Seletiva do Litoral: conflitos, mudanças e permanências da localidade do cumbuco (CE). Dissertação (Mestrado em Geografia) - Centro de Ciências, Universidade Federal do Ceará, Fortaleza.

CEARÁ enaltecido nacionalmente. (1988) O Povo, Fortaleza, 12 ago. 1988. p. 6 CONSTRUTORA CUMBUCO LTDA. (1997) História resumida do Cumbuco. Fortaleza.

CRUZ, Rita de Cássia A. (2002) Política de Turismo e Território. São Paulo: Contexto.

CUMBUCO vai a Cannes. (1986) O Povo, Fortaleza, 12 out. 1986. p. 4.

DANTAS, Eustógio W. C. (2002) Mar à Vista. Estudo da Maritimidade em Fortaleza. Fortaleza: Museu do Ceará.

. (2003) Histórico da Ocupação da Zona Costeira. In: CAMPOS, Alberto A. (coord.) et al. A Zona Costeira do Ceará:Diagnóstico para a Gestão Integrada. Fortaleza: Aquasis. pp. 140-151.

(2006) "Litoralização" do Ceará: Fortaleza, da "Capital do Sertão" a "Cidade do Sol". In: SILVA, José B. da; DANTAS, Eustógio W. C.; ZANELLA, 
Maria E.; MEIRELES, Antônio J. de A. (orgs.). Litoral e Sertão: natureza e sociedade no nordeste brasileiro. Fortaleza: Expressão gráfica. pp. 245-252.

. (2007) O Pescador na Terra. In: SILVA, José B.; CAVALCANTE, Tércia C.; DANTAS, Eustógio W. C. (orgs.). Ceará: um novo Olhar Geográfico. Fortaleza: Edições Demócrito Rocha. pp. 15-27.

. (2010) Geografia do Litoral [Disciplina]. Fortaleza: Programa de PósGraduação em Geografia da Universidade Federal do Ceará.

DIEGUES, Antonio C. S. (1995) Povos e mares: leituras em sócio-antropologia marítima. São Paulo: NUPAUB-USP.

. (1996) O Mito moderno da natureza intocada. São Paulo: Ed. Hucitec.

(2005) Aspectos Sócio-Culturais e Políticos do uso da Água. In: Plano

Nacional de Recursos Hídricos. Brasília: Ministério do Meio Ambiente, 2005.

HAESBAERT, Rogério. (1995) Desterritorialização: Entre as redes e os aglomerados de Exclusão. In: CASTRO, Iná de; CORRÊA, Roberto L.; GOMES, Paulo C. (orgs.). Geografia: Conceitos e Temas. Rio de Janeiro: Bertrand Brasil. pp. 165-205.

. (2002) Territórios Alternativos. São Paulo e Niterói: Contexto e EdUFF.

(2004) Precarização, Reclusão e "Exclusão" Territorial. Terra Livre, Goiânia, v. 2, no 23. pp. 35-51.

. (2005) Da Desterritorialização à Multiterritorialidade. In: X Encontro de Geógrafos da América Latina. São Paulo: Anais do X Encontro de Geógrafos da América Latina. pp. 6774-6792.

. (2007) Território e Multiterritorialidade: um debate. GEOgraphia, Niterói, v. $9, n^{\circ} 17$. pp. $19-45$.

. (2009) Dilema de Conceitos: Espaço-Território e Contenção Territorial. In: SAQUET, Marcos Aurélio; SPOSITO, Eliseu Savério (orgs.). Territórios e Territorialidades: teorias, processos e conflitos. São Paulo: Expressão Popular. pp. 95-120.

(2010) Regional-global: dilemas da região e da regionalização na Geografia contemporânea. Rio de Janeiro: Bertrand Brasil.

HAR VEY, David. (2005) O Novo Imperialismo. São Paulo: Loyola.

INSTITUTO DE PESQUISA E ESTRATÉGIA ECONÔMICA DO CEARÁ. (2008) Perfil básico municipal de Caucaia. Fortaleza.

KNAFOU, Remy. (2001) Turismo e território. Para um enfoque científico do turismo. In: RODRIGUES, Adyr B. Turismo e geografia: reflexões teóricas e enfoques regionais. $3^{\mathrm{a}}$ ed. São Paulo: Hucitec.

LEFEBVRE, Henri. (1991) A vida cotidiana no mundo moderno. São Paulo: Ed. Ática.

(1999) A cidade do capital. Rio de Janeiro: DP\&A.

. (2001) O direito à cidade. São Paulo: Centauro. 
LIMA, Maria do Céu de. (2002) Comunidades Pesqueiras Marítimas no Ceará: território, costume e conflitos. Tese (Doutorado em Geografia) - Faculdade de Filosofia, Letras e Ciências Humanas, Universidade de São Paulo, São Paulo. . (2006) Pescadoras e Pescadores artesanais do Ceará: modo de vida, confrontos e horizontes. MERCATOR, Fortaleza, v. 05, $\mathrm{n}^{\circ}$ 10. pp. 39-54.

NÚMEROS do Litoral Oeste. (2011) O Povo, Fortaleza, 22 ago. 2011. Disponível em:

<http://www.opovo.com.br/app/colunas/verticals/a/2011/07/22/noticiasverticalsa,2 270098/numeros-do-litoral-oeste.shtml>. Acessado: 16 mai. 2012.

NEVES, Berenice A. de C. (2004) Pertencer à nação brasileira: a jangada de São Pedro rumo à Capital Federal (1941). Cadernos AEL: Populismo e Trabalhismo, v. 11, no 20/21. pp. 41-81.

O RENASCER das alegrias e de todas as belezas. (1979) O Povo, Fortaleza, 30 nov. 1979.

PEREIRA, Alexandre de Q. (2006) Veraneio marítimo e expansão metropolitana no Ceará: Fortaleza em Aquiraz. Dissertação (Mestrado em Geografia) - Centro de Ciências, Universidade Federal do Ceará, Fortaleza.

PESCADORES estão cada vez mais longe do mar. Pressionados, eles cedem espaço para mansões. (1986) O Povo, Fortaleza, 7 fev. 1986. p. 7.

PINHO, Elizabeth M. M. (1981) A atuação do Capital imobiliário em um distrito pequeno Cearense. Monografia (Graduação em Sociologia) - Centro de Humanidades, Universidade Federal do Ceará, Fortaleza.

ROBIRA, Rosa T. (2005) Áreas metropolitanas espaços colonizados. In: CARLOS, Ana Fani A.; CARRERAS, Charles (orgs.). Urbanização e mundialização: estudos sobre a metrópole. São Paulo: Contexto.

SECRETARIA DE TURISMO DO ESTADO DO CEARÁ. (2003) Plano de desenvolvimento integrado do turismo sustentável no polo Costa do Sol. Fortaleza. . (2009a) Evolução recente do Turismo no Ceará. Fortaleza. . (2009b) Indicadores Turísticos 1995/2008. Fortaleza. . (2012) Indicadores Turísticos 1995/2011. Fortaleza.

TELES, Glauciana A. (2003) Dinâmicas Metropolitanas Contemporâneas: Caucaia na Região Metropolitana de Fortaleza. Dissertação (Mestrado em Geografia) - Centro de Ciências e Tecnologia, Universidade Estadual do Ceará, Fortaleza.

VIEIRA, Maria E. (2000) Turismo, produção do espaço e desenvolvimento local no litoral oeste cearense - o caso do Cumbuco. Dissertação (Mestrado em Geografia), Universidade Federal do Rio de Janeiro. 